\title{
HYPERPROLACTINEMIA AS A SIDE EFFECT OF LONG-ACTING INJECTABLE RISPERIDONE THERAPY OR A SYMPTOM OF KLINEFELTER SYNDROME - A DIAGNOSTIC AND THERAPEUTIC DILEMMA
}

\author{
Nera Zivlak-Radulovic, Visnja Banjac \& Mirjana Miskovic \\ Psychiatric Clinic, University Clinical Center of the Republic of Srpska, Banjaluka, Bosnia and Herzegovina
}

received: 10.10.2017;

revised: 5.1.2018;

accepted: 18.1 .2018

\section{INTRODUCTION}

Risperidone, as a potent antagonist of the serotonin 5-HT2 receptors, as well as of the dopamine D2 receptors, is presumed to have a major antipsychotic effect. Treatment of patients with acute psychosis most often includes the use of long-acting injectable risperidone. A number of placebo-controlled studies have shown that risperidone solution is well tolerated and that it has many advantages, including a rapid elimination of both positive and negative symptoms of schizophrenia, as well as a low risk of experiencing extrapyramidal symptoms, compared to therapies with classic antipsychotics such as Haloperidol (Yosimura 2005). However, Risperidone can block the D2 receptors in the pituitary gland resulting in hyperprolactinemia, which is dosedependent (Timotijevic 2008).

Klinefelter syndrome belongs to a group of congenital primary hypogonadisms and it is a disorder which affects the development and structure of the testicles. It is the most common form of disorder of sexual differentiation which affects 1 in 500 men and is due to the presence of one or more extra copy of the $\mathrm{X}$ chromosomes in each cell, usually a karyotype is $47, \mathrm{XXY}$ (classic shape) or $46, \mathrm{XY} / 47, \mathrm{XXY}$ (mosaicism). Klinefelter syndrome is characterized by small, hard testicles, azoospermia, gynecomastia, a low level of testosterone (testosterone is the hormone that directs male sexual development before birth and during puberty and low level can lead to delayed or incomplete puberty), and a high level of gonadotropin in the plasma of males with two or more $X$ chromosomes (Harrison et al. 2004). The clinical diagnosis of this syndrome is not easy to discern, which makes it hard to recognize children with Klinefelter syndrome symptoms at an early age. Often the first signs of the syndrome are noticed at puberty in form of insufficiently developed secondary sexual characteristics and gynecomastia. Sometimes it can be detected at an older age, during infertility testing. Children with this syndrome can have a low IQ or mild retardation, and they tend to be taller than their peers at this age (Stepanovic et al. 2001). The other characteristics entail psychosocial problems, a greater tendency towards malignant diseases and a high risk of cardiovascular diseases (Jaksic 2008).

This case study reviews the dilemma the authors encountered during the treatment of psychotic disorder. Was hyperprolactinemia caused by long-active injectable risperidone or was it a symptom of Klinefelter syndrome?

\section{CASE REPORT}

A male patient, aged 28, was sent from the place where he lived to a reference institution for the continuance of treatment for experiencing psychiatric symptoms belonging to unspecified psychotic disorders. During the psychiatric treatment at the parent institution the patient received antipsychotic therapy (promazine taken orally daily $-100 \mathrm{mg} 3 \times 1 / 2$ and long-acting injectable risperidone - one ampoule of $50 \mathrm{mg}$ ), anxiolytic therapy (Clonazepam - one pill of $0.5 \mathrm{mg}$ in the evening) and antidepressant therapy (maprotilin - half the pill of $25 \mathrm{mg}$ in the morning and at noon). The patient experienced psychological improvement upon the completion of therapy, but there were still occasional symptoms of anxiety, mood swings, depersonalization and derealization phenomena. All the symptoms started nine years ago when his father died of leukemia, his mother, sister and brother were all well, according to the family anamnesis. He reported no history of illnesses that could be relevant to the anamnesis and heredity. He also negated any history of smoking or drinking alcohol.

The first examination showed signs of gynecomastia and less body hair. The patient indicated in his autohistory that he noticed some changes on his breasts and a lack of male hair growth at the age of 15 , around the time when the family first consulted a doctor, but no further testing was carried out. Since the patient had already started therapy with long-acting injectable risperidone (patient was administered with risperidone for one year at the parent institution), which on the other hand can result in gynecomastia due to oversecretion of prolactin, the authors decided to examine the hormonal balance of the patient and agree upon whether to 
continue or discontinue therapy. The patient was then referred to an endocrinologist who decided that the patient needed to be hospitalized at the Endocrinology and Complete Diagnostics. The MRI of the pituitary gland showed in the anterior pituitary a hypointense zone of $3.6 \times 2.8 \mathrm{~mm}$ in diameter, which grew in intensity after Gadovist contrast (an adenoma with a permanent prolactin hypersecretion was found). The karyotype test of the patient was $47, \mathrm{XXY}$ (picture 1). The tests on hormonal balance showed the following reference ranges: the prolactin level was $1326 \mathrm{uIU} / \mathrm{ml}$ at 8 a.m., $1197 \mathrm{uIU} / \mathrm{ml}$ at 11 a.m., $1217 \mathrm{uIU} / \mathrm{ml}$ at 4 p.m. (reference range $86-324 \mathrm{uIU} / \mathrm{ml}$ ); the testosterone level was $0,64 \mathrm{ng} / \mathrm{ml}$ (reference range $2.50-8.36 \mathrm{ng} / \mathrm{ml}$ ); the cortisol level was $844 \mathrm{nmol} / \mathrm{L}$ at 8 a.m., $560 \mathrm{nmol} / \mathrm{L}$ at 4 p.m., $202 \mathrm{nmol} / \mathrm{L}$ at 12 a.m. (reference range 175-536 $\mathrm{nmol} / \mathrm{L}$ ); the luteinizing hormone level was 15.5 $\mathrm{mIU} / \mathrm{ml}$ (reference range 1.7-8.6 $\mathrm{mlIU} / \mathrm{ml}$ ); the folliclestimulating hormone level was $33.9 \mathrm{mlIU} / \mathrm{ml}$ (reference range $1.5-12.4 \mathrm{mIU} / \mathrm{ml}$ ); the estradiol level was $<5$ $\mathrm{pg} / \mathrm{ml}$ (reference range 7.63-42.6 pg/ml); progesterone level of was $1.46 \mathrm{ng} / \mathrm{ml}$ (reference range $0.20-1.40 \mathrm{ng} / \mathrm{ml}$ ); the adrenocorticotropic hormone level was $70 \mathrm{pg} / \mathrm{ml}$ (reference range 7-36 pg/ml); the thyroid-stimulating hormone level was $1.62 \mathrm{uIU} / \mathrm{ml}$ (reference range 0.27-4.2 $\mathrm{uIU} / \mathrm{ml}$ ); the thyroid hormone level was $18 \mathrm{pmol} / \mathrm{L}$ (reference range $12-22 \mathrm{pmol} / \mathrm{L}$ ); the antibodies level against thyroid peroxidase was $23 \mathrm{IU} / \mathrm{ml}$ (reference range 0-34 $\mathrm{IU} / \mathrm{ml}$ ); the calcitonin level was $1.90 \mathrm{pg} / \mathrm{ml}$ (reference range $0.0-14.3 \mathrm{pg} / \mathrm{ml}$ ); the parathyroid hormone level was $48 \mathrm{pg} / \mathrm{ml}$ (reference range $15-65 \mathrm{pg} / \mathrm{ml}$ ).

The ultrasound of the scrotum showed that the right testicle was $1.9 \times 0.9 \mathrm{~cm}$ in diameter, homogeneous, with a small epidermoid cyst, and the left testicle was $1.8 \mathrm{x} 1$ $\mathrm{cm}$ in diameter, homogeneous, with a small amount of calcification. For further diagnostics of the epidermoid cyst the following markers were tested: the level of lactate dehydrogenase was $176 \mathrm{U} / \mathrm{L}$ (normal values $<241 \mathrm{U} / \mathrm{L}$ ), the level of alpha-fetoprotein was $2.2 \mu \mathrm{g} / \mathrm{L}$ (normal values $<9.92 \mu \mathrm{g} / \mathrm{L}$ ) and the level of beta-hCG was $<0.1$. The level of glycosylated hemoglobin was A1C 5.9\% (reference range 4\%-5.9\%). Osteodensitometry results were as follows: AP spine L1-L4 - Z score 2.9, L1-L4 - Z score 2.8-3.1. The ultrasound of the thyroid gland showed that it was of normal size and echostructure, in the left lobe 2 peripheral hypoechogenic changes $6 \mathrm{~mm}$ in size were found. The dimensions were following: the right lobe was $1.53 \times 1.94 \times 3.66 \mathrm{~cm}$; the left lobe was $1.19 \times 1.85 \times 3.93 \mathrm{~cm}$, isthmus was 0.3 $\mathrm{cm}$. All the other somatic and neurological tests were normal. During his hospitalization the patient was diagnoses with Klinefelter syndrome. Hormonal balance showed primary hypogonadism (a high level of gonadotropins with a low level of testosterone), a high level of cortisol with a preserved diurnal rhythm of cortisol, but an inadequately high level of adrenocorticotropic hormone. Osteodensitometry clearly showed the presence of osteoporosis. Testosterone was administered via am- poules (one ampoule of $250 \mathrm{mg}$ for four weeks) which the patient responded well to, bromocriptine pills of 2.5 mg 2x1. The therapy was prescribed by a psychiatrist. The psychological status of the patient during hospitalization was satisfactory except for somewhat more manifested uneasiness caused by the news delivered to him at the Genetic Counseling Center that he wouldn't be able to procreate.

Since his discharge from the hospital the patient has kept regular appointments with a psychiatrist and an endocrinologist. His psychological status is satisfactory and he continues to receive the same therapy. In terms of hormonal balance, the patient responds well to testosterone therapy, however, prolactin levels are still high (8 a.m./11 a.m./4 p.m.): 1311 uIU/ml, 985 uIU/ml, $1371 \mathrm{uIU} / \mathrm{ml}$, which led to the increase in the dosage of bromocriptine, one pill 3 times a day until the next examination.

\section{DISCUSSION}

Despite the fact that Klinefelter syndrome is one of the most common chromosomal disorders manifested in men, it often goes unrecognized due to variations in clinical diagnosis. The diagnosis percentage is very low during childhood and only $10 \%$ of cases are registered until puberty, and $25 \%$ of cases are registered in adulthood (Bojesen et al. 2003). Our patient was also diagnosed with Klinefelter syndrome at the age of 28 . Earlier researches have shown that the persons with Klinefelter syndrome are at risk for developing some sort of psychiatric disorder including depression, anxiety, schizophrenia and other forms of psychotic disorders (DeLisi et al. 2005, Boks et al. 2007, Bruining et al. 2009). In this case study the patient experienced the symptoms of psychotic disorders. In a case study conducted by Bruining (2009) psychiatric interviews and observations showed that out of 51 boys with Klinefelter syndrome who participated in the study almost half of them (45\%) experienced psychotic symptoms, predominantly auditory hallucinations and paranoid delusions. Four of the participants (8\%) were diagnosed with unspecified psychotic disorders, according to the DSM-IV classification (Bruining et al. 2009). Although some of the mentioned studies are limited by a small number of specimens, the prevalence of psychiatric disorders is rather high than it is usually observed in men in the general population (Turriff et al. 2011).

Our patient was also diagnosed with hyperprolactinemia and gynecomastia. A few case reports and studies have been published regarding the hyperprolactinemia in Klinefelter syndrome (Xu et al. 2011, Pinto et al. 1996, Kumanov 1995, Takeuchi et al. 1999). A number of studies have tried to find a possible underlying disorder in the hypothalamo-pituitary-thyroid axis in patients with Klinfelter syndrome. However, those reports were contradictory and failed to locate a unique defect in the axis. According to the examination carried 
out in 1996, the prolactin level was elevated with a slight over-response to thyrotropin-releasing hormone. Estrogen is known to augment prolactin secretion (Takeuchi et al. 1999).

Gynecomastia (GM) is characterized by enlargement of the male breast, caused by glandular proliferation and fat deposition. The etiology of GM is attributable to physiological factors, endocrine tumors or dysfunctions, non-endocrine diseases, drug use or idiopathic causes. Klinefelter syndrome is associated with hypogonadism and infertility; in these men, GM is seen in almost $70 \%$. The reason why the presence of an extra $\mathrm{X}$ chromosome is linked to GM is unclear. A hormonal imbalance between estrogens and androgens is the key hallmark of GM generation. Another hormonal action that stimulates breast tissue in men is observed secondary to hyperprolactinemia. Prolactin receptors have been demonstrated in GM, and hyperprolactinemia probably plays an indirect role in GM, since it causes central hypogonadism and alters the androgen/estrogen ratio. However, it is clear that most men with GM do not have elevated serum prolactin levels and not all men with hyperprolactinemia develop GM (Barros \& Sampaio 2012). Pituitary adenomas producing prolactin (prolactinomas) may also induce GM (Johnson \& Murad 2009). Other endocrine-metabolic conditions related to the development of GM include metabolic syndrome, refeeding after severe starvation and substantial weight loss and functional hyperprolactinemia (Narula \& Carlson 2007). Nuclear magnetic resonance was used to diagnose a pituitary adenoma with a permanent prolactin hypersecretion in our patient. Prolactin-secreting tumors have been reported in Klinefelter syndrome patients (Kumanov et al. 1995, Pinto et al. 1996). It is reasonable to assume that because of the loss of negative feedback effect, chronic stimulation of lactotroph cell type would result in hyperplasia, which in turn may transform into adenoma. Therefore, it remains to be elucidated whether hyperplasia of the pituitary occurs secondary to gonadal failure or is caused by a genetic abnormality linked to Klinefelter syndrome (Abdel-Razic et al. 2012).

The connection between antipsychotics and hyperprolactinemia has been discussed ever since the '70s of the last century (Gianfrancesco et al. 2009). When it comes to hyperprolactinemia, it is regarded as a pathological phenomenon if prolactin levels in blood are constantly high in the absence of pregnancy and lactation. Hyperprolactinemia can pose a medical problem due to acute and chronic consequences in form of: dysmenorrhea, galactorrhea, gynecomastia, sexual dysfunction, a high risk of osteoporosis and development of pituitary tumors (Haddad \& Wieck 2004, Montejo 2008, Szarfman et al. 2006). Antipsychotics are the most common cause of pharmacologic hyperprolactinemia, and the majority of antipsychotic agents cause hyperprolactinemia. Classification of antipsychotic drugs may be based on their prolactin-elevating aptitude: classical antipsychotics are traditionally "prolactin-raising”, while the newest class is usually "prolactin-sparing" (Bostwick et al. 2009). A cohort study from 2007 reported that among 194 schizophrenia and bipolar patients receiving antipsychotics from a single community mental health facility in the UK, 38\% had prolactin levels above the upper limit of normal, two thirds of whom had significantly elevated levels with clinical consequences. Women were particularly at risk for elevations and associated consequences, with over $50 \%$ of women in the study having abnormal prolactin levels (Bushe \& Shaw 2007).

Typical antipsychotics, acting as nonselective antagonists of prolactin receptors and have a high potential of causing hyperprolactinemia. In general, a prolactin level among patients treated with classical antipsychotics (Haloperidole, Fluphenazine, etc.) increase few hours after starting the treatment and continues throughout its duration. Conversely, the risk of hyperprolactinemia caused by atypical antipsychotics varies depending on the active substance used. Thus, amisulpride, risperidone and paliperidone have a strong potential to cause hyperprolactinemia while clozapine, olanzapine, quetiapine, and aripiprazole have the least potential (Marrag1 et al. 2015). All atypical antipsychotics increase prolactin levels by blocking the D2 receptor through the tuberoinfudibular dopaminergic pathway (Knegtering et al. 2003). The effects atypical antipsychotics have on prolactin levels are never similar and the same for everybody. Among atypical antipsychotics, the use of Risperidone is connected with the highest prolactin levels in serum (Perkins 2004, Komossa et al. 2011). Research has shown that 9-xydroxyrisperidone (active metabolite of Risperidone) most commonly causes hyperprolactinemia (Knegtering et al. 2005, Tollefson et al. 1997). The incidence of the side effects related to hyperprolactinemia, such as menstrual irregularities, galactorrhea, sexual dysfunction, amenorrhea and gynecomastia during Risperidone treatment ranges 1-10\% (Madhusoodanan, Parida and Jimenez 2010). There is evidence that many patients (53-85\%) who use long-acting injectable risperidone suffer from hyperprolactinemia (Bushe et al. 2008, Doknic et al. 2011, Bushe \& Shaw 2007). Hyperprolactinemia is dosedependent even when it comes to the use of long-acting injectable risperidone (Canuso et al. 2003).

There has been considerable debate over the years on the impact of hyperprolactinemia on patients with schizophrenia. High prolactin levels in these patients are frequently associated with sexual dysfunction, osteoporosis and even breast cancer (Peuskens et al. 2014). Management of antipsychotic-induced hyperprolactinemia should be on a case-by-case basis (Miyamoto et al. 2015). The primary goal of therapy in patients with hyperprolactinaemia is to restore gonadal and sexual function, to prevent inappropriate lactation and bone demineralization from inadequate sex steroids by normalising prolactin concentration levels. Only in 
cases where the causative agent cannot be reduced in dose, discontinued or switched to an alternative, should pharmacological treatment be employed. Before add-on therapy is considered, aripiprazole monotherapy should be evaluated and tried where possible. There are a few studies which have demonstrated the effectiveness of aripiprazole as an add-on to normalise prolactin levels. The dose of aripiprazole is $5 \mathrm{mg}$ with prolactin levels measured weekly to ascertain benefit. However, it might be a consideration for patients in whom the risks of switching to an alternative antipsychotic with a lower potential to raise prolactin are significant, and where the risks of maintaining a raised prolactin are also high (The Sussex NHS Foundation Trust Guidance 2014). On the other hand, recent research has shown that hyperprolactinemia can be found in patients experiencing the first psychotic episode but not taking any antipsychotics. This present vulnerability and genetic predisposition have to be taken into account when considering the use of antipsychotics and their possible side effects (Peuskens et al. 2014). Another important thing that some researches point out to is that the pituitary gland represents a dynamic organ whose volume increases months before the onset of the first psychotic episode and independently from the use of antipsychotics (Pariante 2008). Several studies support the thesis that the hyperactivity of the pituitary gland and its weak response are caused by stress combined with the onset of psychosis (Borges et al. 2013, Baumeister et al. 2014).

In this case study it was very difficult to determine what exactly caused hyperprolactinemia, whether the side effects were caused by the use of long-acting injectable risperidone, or Klinefelter syndrome per se.

It is precisely because of these reasons that it is very important to take into account multiple factors underlining the use of risperidone, which can lead to high prolactin levels in serum and clinical signs of hyperprolactinemia (Margari et al. 2015). In the case of our patient perhaps a different kind of psychotics should be taken into consideration since the prolactin levels are still high despite the bromocriptine therapy.

\section{Acknowledgements: None.}

Conflict of interest: None to declare.

\section{Contribution of individual authors:}

Nera Zivlak Radulović is a author, who has contributed to the idea and form, the methods of performing the article and critical correction of the paper, as well as to writing the paper.

Višnja Banjac is a co-author, who has contributed to the methods of performing the article, obtaining and collecting the data and writing the paper.

Mirjana Mišković is the co-author who has contributed writing the paper.

\section{References}

1. Abdel-Razic MM, Abdel-Hamid IA, Elsobky E, El-Dahtory F: Further Evidence of the Clinical, Hormonal and Genetic Heterogeneity of Klinefelter Syndrome:A study of 216 Infertile Egyptian Patients J Androl 2012; 33:441-8.doi: 10.2164/jandrol.110.011536. Epub 2011 Jul 14

2. Baumeister D, Lightman SL, Pariante CM: The interface of stress and the HPA axis in behavioural phenotypes of mental illness. Curr Top Behav Neurosci 2014, 18:13-24

3. Barros ACSD, Sampaio MCM. Gynecomastia: physiopathology, evaluation and treatment. Sao Paulo Med J 2012; 130:187-97

4. Bojesen A, Juul S, Gravholt CH: Prenatal and postnatal prevalence of Klinefelter syndrome: a national registry study. J Clin Endocrinol Metab 2003; 88:622-6

5. Boks MP, de Vette MH, Sommer IE, et al.: Psychiatric morbidity and X-chromosomal origin in a Klinefelter sample. Schizophr Res 2007; 93:399-402

6. Borges $S$, Gayer-Anderson C, Mondelli V: A systematic review of the activity of the hypothalamic-pituitaryadrenal axis in first episode psychosis. Psychoneuroendocrinology 2013; 38:603-611

7. Bostwick JR, Guthrie SK, Ellingrod VL: Antipsychoticinduced hyperprolactinemia. Pharmacotherapy 2009; 29:64-73. doi: 10.1592/phco.29.1.64

8. Bruining $H$, Swaab $H$, Kas $M$, van Engeland $H$ : Psychiatric Characteristics in a Self-Selected Sample of Boys With Klinefelter Syndrome. Pediatrics 2009; 123:e865-e870

9. Bushe C, Shaw M: Prevalence of hyperprolactinaemia in a naturalistic cohort of schizophrenia and bipolar outpatients during treatment with typical and atypical antipsychotics. J Psychopharmacol 2007; 21:768-73

10. Bushe C, Shaw M, Peveler RC: A review of the association between antipsychotic use and hyperprolactinaemia. $J$ Psychopharmacol 2008; 22(2 Suppl):46-55

11. Canuso CM, Bossie CA, Lasser RA, et al.: Reduced serum prolactin levels after treatmetn with long-acting risperidone. Poster at 156th APA congress, San Francisco, 2003

12. DeLisi LE, Maurizio AM, Svetina C, et al.: Klinefelter's syndrome $(X X Y)$ as a genetic model for psychotic disorders. Am J Med Genet B Neuropsychiatr Genet 2005; 135B:15-23

13. Doknic M, Maric NP, Britvic D, et al.: Bone remodeling, bone mass and weight gain in patients with stabilized schizophrenia in real-life conditions treated with longacting injectable risperidone. Neuroendocrinology 2011; 94:246-54

14. Gianfrancesco FD, Pandina G, Mahmoud R, et al.: Potential bias in testing for hyperprolactinemia and pituitary tumors in risperidone- treated patients: a claimsbased study. Ann Gen Psychiatry 2009; 8:5

15. Haddad PM, Wieck A: Antipsychotic-induced hyperprolactinaemia: mechanisms, clinical features and management. Drugs 2004; 64:2291-314

16. Harrison et al.: Harisonova načela interne medicine. Knj.2. Beograd:Bard-fin; Banjaluka: Romanov 2004; 2173

17. Jaksic J: Visok rast. Paediatr Croat 2008; 52(Supl 1):81-87

18. Johnson RE, Murad MH: Gynecomastia: pathophysiology, evaluation, and management. Mayo Clin Proc 2009; 84:1010-5 
19. Knegtering H, van der Moolen AE, Castelein S, Kluiter H, van den Bosch RJ: What are the effects of antipsychotics on sexual dysfunctions and endocrine functioning? Psychoneuroendocrinology 2003; 28:109-23

20. Knegtering $R$, Baselmans $P$, Castelein $S$, Bosker F, Bruggeman R, van den Bosch RJ: Predominant role of the 9-hydroxy metabolite of risperidone in elevating blood prolactin levels. Am J Psychiatry 2005; 162:1010-2

21. Komossa K, Rummel-Kluge C, Schwarz S, Schmid F, Hunger H, Kissling W, Leucht S: Risperidone versus other atypical antipsychotics for schizophrenia. Cochrane Database Syst Rev 2011; 1:CD006626

22. Kumanov P: Increased prolactin secretion and thyrotrophin response to thyrotrophin releasing hormone in Klinefelter's syndrome. Andrologia 1995; 27:41-5

23. Madhusoodanan S, Parida S, Jimenez C: Hyperprolactinemia associated with psychotropics-a review. Hum Psychopharmacol 2010; 25:281-97

24. Margari L, Matera E, Petruzzelli GM, Simone M, Lamannaa AL, Pastoreb A, Palmieric VO and Margarib F: Prolactin variations during risperidone therapy in a sample of drug-naive children and adolescents. Int Clin Psychopharmacol 2015; 30:103-108

25. Marrag I, Haiji K, Braham MY, Dhifallah M, Nasr M: Antipsychotics and Hyperprolactinemia: Prevalence and Risk Factors. Ann Psychiatry Ment Health 2015; 3:1047

26. Miyamoto BE, Galecki M, Francois D: Guidelines for Antipsychotic-Induced Hyperprolactinemia. PsychiatrAnn. 2015; 45:266-272

27. Montejo AL: Prolactin awareness: an essential consideration for physical health in schizophrenia. Eur Neuropsychopharmacol 2008; 18:108-14

28. Narula HS, Carlson HE: Gynecomastia. Endocrinol Metab Clin North Am 2007; 36:497-519

29. Pariante CM: Pituitary volume in psychosis: the first review of the evidence. J Psychopharmacol 2008; 22(Suppl):76-81

30. Perkins DO: Antipsychotic-induced hyperprolactinemia: Pathophisology and clinical consequences. Adv Stud Med 2004; 4:982-6
31. Peuskens J, Pani L, Detraux J, De Hert M: The effects of novel and newly approved antipsychotics on serum prolactin levels: a comprehensive review. CNS Drugs. 2014; 28:421-53. doi: 10.1007/s40263-014-0157-3

32. Pinto AC, Czepielewski MA, Gross JL, Mussio W, Lengyel AM: A prolactin-secreting tumor in a patient with Klinefelter's syndrome: a case report. J Endocrinol Invest 1996; 19:248-52

33. Stepanovic R et al.: Pedijatrija. Savremena administracija, Beograd 2001; 100

34. Szarfman A, Tonning JM, Levine JG, Doraiswamy PM: Atypical antipsychotics and pituitary tumors: a pharmacovigilance study. Pharmacotherapy 2006; 26:748-58

35. Takeuchi Y, Murata Y, Sintani J, Masukawa H, Nakamura R, Oi K, Kato Y, Niinomi M: Klinefelter's syndrome accompanied by mixed connective tissue disease and diabetes mellitus. Intern Med 1999; 38:875-81

36. The Sussex Partnership NHS Foundation Trust: Guidance on the Treatment of Antipsychotic Induced Hyperprolactinaemia in Adults, 2014

37. Timotijevic I: Psihofarmakoterapija. Planeta print, Beograd 2008; 177

38. Tollefson GD, Beasley CM Jr, Tran PV, Street JS, Krueger JA, Tamura RN, Graffeo KA, Thieme ME: Olanzapine versus haloperidol in the treatment of schizophrenia and schizoaffective and schizophreniform disorders: results of an international collaborative trial. Am J Psychiatry 1997; 154:457-65

39. Turriff A, Levy HP, Biesecker B: Prevalence and psychosocial correlates of depressive symptoms among adolescents and adults with Klinefelter syndrome. Genet Med 2011; 13:966-72. doi: 10.1097/GIM.0b013e3182227576

40. Xu C, Zhang CY, Chen N, Sun X, Xiao Y, Gao L, Zhao JJ: A case of Klinefelter syndrome with aplastic anemia. Int $J$ Hematol 2011; 93:213-5. doi: $\quad$ 10.1007/s12185-0110767-1. Epub 2011 Feb 5

41. Yoshimura R: An open study of risperidone liquid in acute phase of schizophrenia. Hum Psychopharmacol Clin Exp 2005; 32:244-51

Correspondence:

Nera Zivlak-Radulovic, MD, PhD, Forensic Psychiatrist

Psychiatric Clinic, University Clinical Center of the Republic of Srpska

Macvanska 17, 78000 Banjaluka, Bosnia and Herzegovina

E-mail: slobodanrad52@teol.net 